\title{
The Application of Traditional and Innovative Technologies in Studio Furniture
}

\author{
Jun Wang $^{1}$, Zhi hui $\mathrm{Wu}^{2}$ \\ ${ }^{1}$ College of Furniture and Industrial Design, Nanjing Forestry University, Nanjing 210037,China \\ ${ }^{2}$ College of Furniture and Industrial Design, Nanjing Forestry University, Nanjing 210037,China \\ 1wangjun_917@163.com \\ 2wzh550@sina.com
}

Keywords: Craft; material; technology; studio furniture; CNC

Abstract: It is important to use materials, crafts and technologies to design and manufacture shapes of physical objects, such as furniture. This paper joins pieces of traditional and contemporary studio furniture, decoding them on the basis of material, craft, and computer design technologies. Drawing on Studio furniture maker Wendell Castle and showcase of Night stand chair, it is important for the thesis shows the digital fabrication process that CNC remediated traditional relations of craft and forms of value. It is common to create aesthetical pleasing on the procedure of studio furniture manufacture, while the user focuses on the aesthetics of the design, the computational design framework helps to achieve physical realizability by digital technology. From both the analysis toward traditional relations and new forms of studio's experience, the paper would demonstrate that material and creative practice may pose questions and opportunities for wider digital technology concerns around craft, creativity and manufacture process.

\section{Introduction}

Materials are intertwined in and through the creative process. These forms of entanglement generate the push and pull creativity forward. Such view shifts the logical understandings away from human accents toward materials as integral to the way we live, act, and create in the world. Materiality is integral to organizational life and that developing new ways of dealing with material is critical if one is to understand the multiple, emergent, shifting and interdependent technologies at the heart of contemporary practice. Human actors and technological practices are co-constituted, emerging together from entangled networks that are always shifting and emerging in time.

The materials, tools and practices of creation are moved into abstracted spaces and tensions. The integration the computer into craft-based workflows may shift making into a type of"rule following" that requires a different sort of cognitive disposition than the embodied manipulations of analog tools. For this reason, hybrid practices that intertwine computation and handwork without an embodied, sensual knowledge can be "technologically correct". The computational tools are considered as "extending" tools that allow forms and ideas to be materialized in new and concrete ways. Good craft can be found in any human undertaking from furniture making to software engineering.

The incorporation of mechanical tools meant to replace, augment, or assist human labor and skill have long played a central and contused role in the evolution and meaning of art, craft, and handwork process. Studio furniture is distinguished from the mass production products. It is intersected with design and sculpture, and has an affinity with other materials, such as ceramics and metals. Good furniture design is usually still a case from following function. Within that parameter a design has to develop a style, but it should be in the service of utility.

\section{Traditional studio furniture design}

\subsection{Focus on materials}

Material agency is witnessed and enacted through dialogues that unfold between human and material elements within complex social material practices. In this way, the agency of material and objects is 
seen as becoming through object negotiation and social material interaction. In a similar light, it is proved that materials, information, techniques, and human relationships are bound and rebound in a "crossbred" network, which blurs and reconciles the logical "gap" between digital and physical environments.

Wood is a compelling and natural material for the furniture makers that it's easy to spend a design with nothing else. Wood's range of textures, colors, its strength and warmth, along with the panoply of specialized machines, tools and techniques required to manipulate wood with mastery, connect the maker to the material in a harmonious way. Wharton Esherick sculpted the free-form pieces of furniture, using traditional woodworking techniques (see fig. 1). Esherick's work was considered personal and retained a strong sculptural reference. The work has a beautiful forms and in exposing the natural beauty of the material itself. The concept of beauty emulated the values of traditional sculpture. His work expressed a desire to incorporate function into the aesthetic experience[1]..

Sam Maloof uses traditional design motifs to add a reassuring resonance to his contemporary designs. The rocking chair of Sam Maloof draws on familiar images of traditional porch rockers and Windsor chair, shaping the joints to create flowing, curvilinear forms (see fig. 2). The furniture is sculpture as well as functional object, contemporary notion. The carved seat and curved back with shaped splits reflect Maloof's sensitivity toward ergonomics, a progressive idea for the time when Maloof began developing these chairs[2].

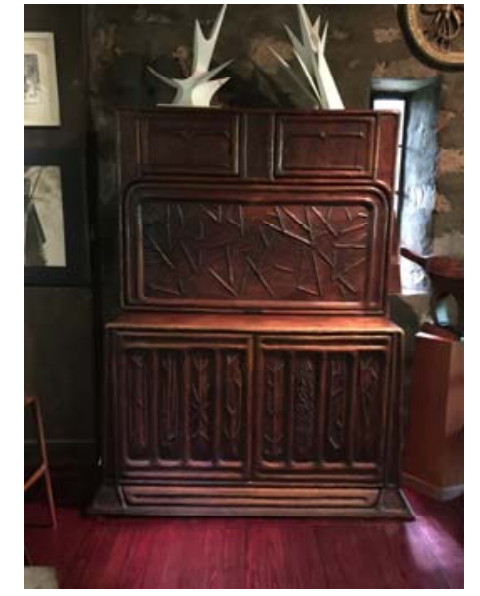

Figure 1: Cabinet

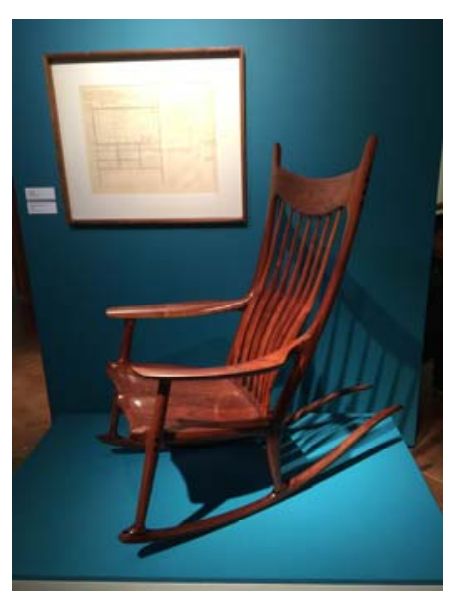

Figure 2: Rocking chair

Over the last decade, a rising number of furniture makers demonstrate a native speaker's fluency in other kinds of materials, besides wood, which including metal, ceramics, plastic, wood and steel came together (see fig. 3). Steel is often harsh, cold and hard. The warmth and tactile quality of wood made predominant of metal. The result a bench made of sheet steel with slatted wooden seats that combine sculptural power with inviting functionality. All the angles for the steel parts are automatically calculated and with CNC laser cutter. In order to bring an element of the unpredictable to the symmetrical designs, the seat slats were cut in random widths. Despite the bulk, the benches are light-weigh with a lot of presence.

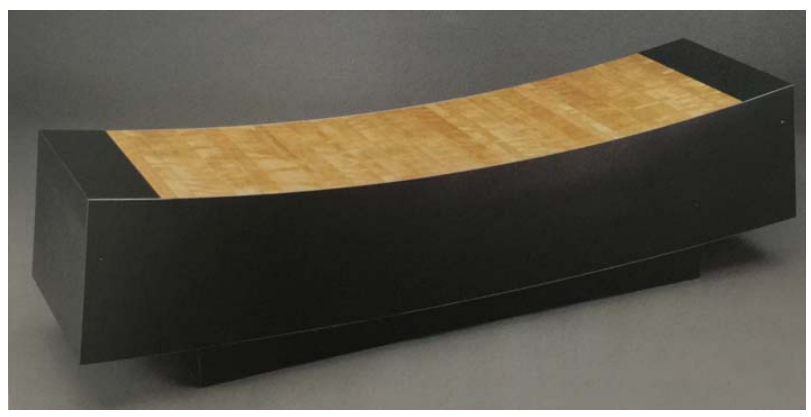

Figure 3: Wood and steel stool 


\subsection{The meaning of craft}

It's important to recognize the inherent qualities of wood as a furniture material. Lamination follows the growth pattern in a tree better than can be achieved with traditional joinery techniques using square milled to thickness lumber. It enables the furniture for new forms that would be strong and have a sense of freedom. Its high tech process that aims for a natural result, such as the furniture designs of Ray and Charles Eames exemplify the formal extreme. Beginning with the experimental sculptural objects cut and then bent from molded plywood splints and ending with the molded shapes of chair seats and backs, it is easy to identify the personalization of their original source of inspiration in the work.

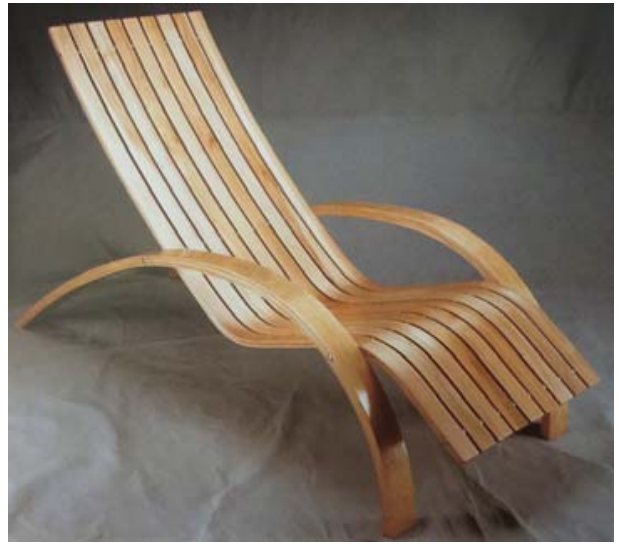

Figure 4: Chaise lounge

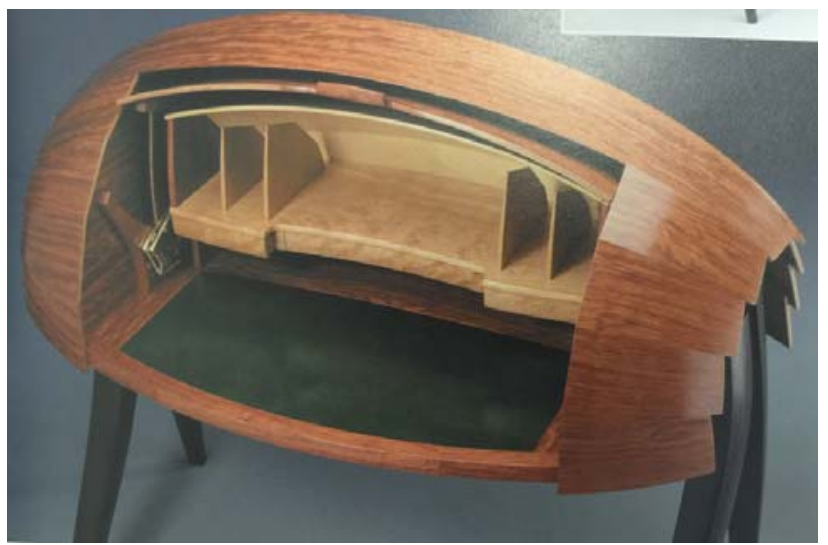

Figure 5:Elliptical desk

The chaise lounge designed and constructed on maple (see fig. 4). The material is indigenous western maple that grows on Vancouver Island. The project meets the challenge of using particularly difficult wood for bent lamination work. All of the bending forms for the chaise components were cut by CNC technology. The contours of the chaise were tested and adjusted using mock-ups and trial fittings. Once the desired curve was obtained, the forms were used in a vacuum bag to create the curved pieces. Jere asgood elliptical desk is finely crafted, for the tapered legs, 1/4 or 5/16inch layers were laminated into a curve. The taper was band sawed through the glue lines (see fig. 5).

In general, the use of specialized techniques shows the perception of significant labor in studio furniture. The wood and metal are combined in structures for furniture. Specialized techniques such as turning and metal casting shift attention away from the tradition.

\section{Digital technologies in studio furniture design}

\subsection{The inspection of digital supplement in Wendell Castle's studio}

The new computational tools and infrastructures are entered into "tradition" processes of artistic and craft-based production. This question has been taken up to explore the dynamics and tensions surrounding the integration of new technological systems and practices into craft and creative design environments. Some of this work has looked towards expanded and active concepts of materiality as a mode of analysis for gaining deeper insights into the interplay between objects and humans at the heart of the creative process[3].

Fine arts and furniture design intersect with digital tools and processes. Post-digital art is a humanizing one, restoring balance and the possibility of a more constructive and even-handed aesthetic relationship between creative handwork and digital work. In a post-digital studio, technological tools and methods are just one of the toolsets artists use, without any particular fascination or anxiety either way. It is the digital made ordinary, even boring-until enlivened by the flow and possibilities of a vibrant aesthetic process[4].

Wendell Castle is a fine arts furniture studio in New York, studio follows test and develop the experience of digital tool. CNC was integrated into the collaborative work practices and material that collectively constitute the process of imagination and production that define the Castle studio and its unique creative process and vision. Castle's pieces are said to invoke grace, beauty, humor and 
comfort while unifying form and function, aesthetics and utility. From the mechanic to the organic, the forms often reference natural or biomorphic shapes that seem to grow directly from the gallery floor. Castle’s work neutralizes categorical boundaries between fine art, industrial design and craft.

\subsection{General methods and evolution}

\section{General methods and evolution of process: 1960-2014}

Castle draws daily with paper and pencil,conceptualizes form by creating a number of uncomplicated 2D sketches. The sketches are numerous and can be seen hanging on walls and covering work surface throughout the studio. These drawings guide his production of small, but accurately scaled, foam models informing the larger wood piece to come. The hand-sized models are carved from thin planks foam glued together. The small foam laminates are sent off-site to a woodworker unaffiliated with the castle workshop who utilizes 3D scanning tools to digitize the model, creating a CAD drawing of the piece. The offsite scanning facility adds line work to the image, marking the wood laminate layers. This image is then sent to the person who manages the studio's computational practices (see fig. 6). These cross sections will be individually printed out on paper using the studio's plotter, resulting in large patterns to inform both the shape of the wood planks to come, as well as their order within the developing laminate block. The layers that make up the laminate block will be cut from Ash, a hard and scratch-resistant wood. Ash is an appropriate if not extravagant choice for furniture.

Evolution of laminates and 3D scanning: 2009-2014

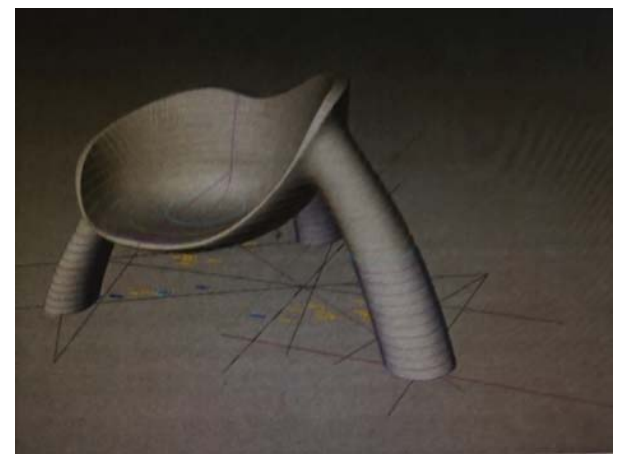

Figure 6: Digital chair

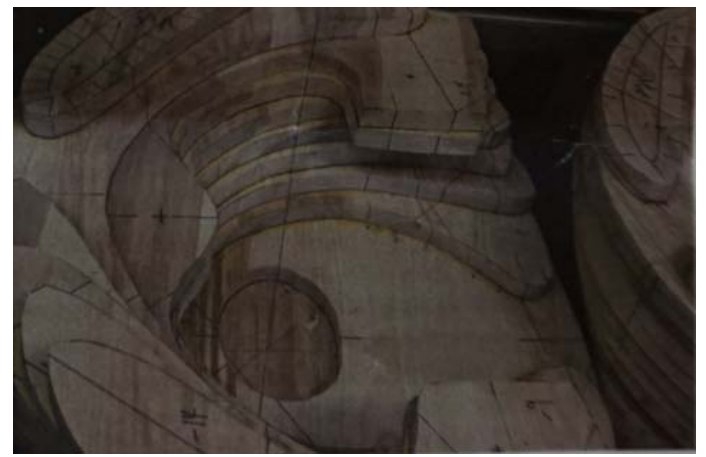

Figure 7: Laminate layers

The 2009 implementation of 3D scanning combed with accurately printed paper patterns. The technology "freed up" the design, while greatly increasing accuracy. Fewer errors were made and less materials, time and energy were lost. The new digital process came with an unanticipated benefit. Within the digital environment, Castle is afforded the ability to consider the furniture object in 3D virtual space before large-scale physical shaping begins. He can make slight adjustments (raising or lowering a seat while instantly exploring the digital result) by tweaking the files. Once decided upon, the patterns and laminates are accurately cut, stacked, glued and clamped into place. A chainsaw wielded by carvers becomes the first physical tool used to reveal the final form (see fig. 7).

\subsection{Finishing the work}

Once the initial carving of laminate block is completed, it is taken a series of sanders and grenadiers to refine and reveal the final form. When the shape is finished, who sands or wire brushes the piece determines the outcome of the surface. It takes 4 days to shape, carve and refine the furniture piece. Chairs went through a "complex and labor intensive finishing process”. Each chair required hand finishing revealing the grain while also opening the wood's pores. After wire brushing, the top showed sanded surface with a number of paper grains. Then the black lacquer and oil filler are capable of reaching deep into the grain. Finally, the abrasive polish was being used in a satin finish, treating the surface till it's dark and deep.

\subsection{Implementing the Robotic carving arm}

The machine was transformed into a 6-axis carving arm (see fig. 8). The robot's new mission is to mill several feet of laminated wood stack quickly and accurately, using $\mathrm{X}$ and $\mathrm{Y}$ reference points to 
identify and enter into its RAPID code. It is important to understand the properties of wood and the constraints and possibilities of software design where most CNC robots are utilized.

The current CNC is working as follows: it begins with CAD file delivered to him by outsourced 3D scanning studio. The file must be translated into a set of CAM (Computer Aided Manufacturing) M and G codes. Theses codes are translated into RAPID code (see fig. 9), the proprietary software language used by the Robotics CNC machine. Once the RAPID codes are ready, the laminate block must be placed properly in the blank space the surrounds the carving reach of the machine. According to the experiment, integrating the machine into the studio practice also came with a sense of hesitation and caution. The robot is doing the function that could be performed by hand. But there is a degree of repeatability here, which could never be achieved manually. It was this degree of repeatability that enabled the studio to produce their first edition of wood furniture pieces.

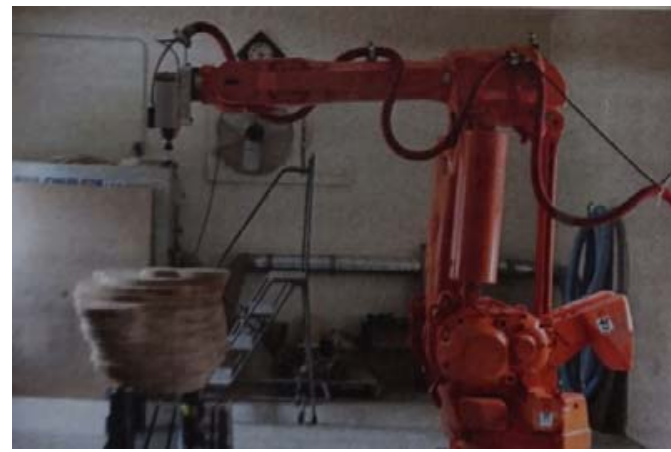

Figure 8: CNC with chair

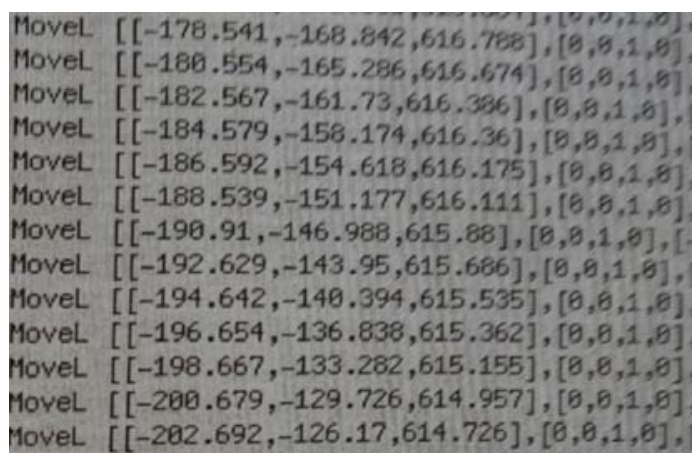

Figure 9: Chair in RAPID code

The machine can mill the laminates in much less time, and it can never address the sensitivities of an organic material the way a human carver can not reach. So, the robot can expand design in three ways: by extending reach, allowing for more complex joinery, creating hollows in solid form. Besides sharing the workload of the carvers by assuming the rough, boring, cuts, the carving arm of the CNC machine can reach underneath, within the wood block to shape a sculpture in ways a human arm could not reach. CNC can free up the vocabulary of furniture design. Additionally, the mechanical arm allows for seamless, previously impossible joinery to be realized[5].

Technological implementation has shifted the nature and location of collaboration, creativity and craft within the studio. The process, growth trajectory and eventual implications of adopting computational tops and systems are still very much in the process of being worked out.

\section{Conclusions}

The paper described the material processing and physical exploration toward studio furniture, in which showing the traditional studio furniture cared more attention to the wooden material that concerned. Through the implementation of digital technology, the studio furniture design realized improved speed, prevision and accuracy within certain crafting processes. The designers and digital fabrication tools are engaged in creative entanglements where technology and human making expand and inform one another.

The introduction of new computational tools into craft-based forms of creative work carries deep implications: both for the experience and organization of work and the values that surround it. It can call the basic tenets of craft and the values assigned to these. It can also pint to new forms of connection and attachment between creative producers and the materials with which they engaged.

\section{Acknowledgements}

This work was financially supported by the Priority Academic Program Development of Jiangsu Higher Education Institutions (PAPD) 


\section{References}

[1]. Mansfield Bascom. Wharton Esherick. New york. Abrams Publishers.2010

[2]. Jeremy Adamson. The furniture of Sam Maloof. Smithsonian American Art Museum Publishers.2001

[3]. Rich Tannen. Grains and losses: learning to live with the digital workshop. Furniture makers exploring digital technologies.2005

[4]. Nobuyuke Umentani. Guided exploration of physically valid shapes for furniture design. Communications of the ACM. September 2015.

[5]. Amy Cheatle. Digital entanglements: craft, computation and collaboration in Fine art furniture production.In press.2014 